\title{
Saaz Special - another hop variety recommended for Czech beer
}

\author{
Alexandr Mikyška ${ }^{1 *}$, Karel Štěrba ${ }^{1}$, Martin Slabý ${ }^{1}$, Marie Jurková ${ }^{1}$, Aleš Kopecký², František Kroupa ${ }^{3}$ \\ 1 Research Institute of Brewing and Malting, \\ Lípová 15, CZ 12044 Prague, Czech Republic \\ 2 Top Hop, Ltd., Jasná I 1341/11, CZ 14700 Prague, \\ Czech Republic \\ 3 V. F. HUMULUS, Ltd., U Odborů 787, CZ 43801 Žatec, \\ Czech Republic \\ ${ }^{*}$ Corresponding author: mikyska@beerresearch.cz
}

\begin{abstract}
The specification of varietal profiles of secondary metabolites of hops in beer is rather important for hop growing and beer brewing. Chemical and sensory profiles of beers hopped with the varieties of Saaz Special and the traditional Saaz semiearly red bine hops (Saaz) were compared in three-year pilot brews (200 L). Single kettle hopped beers and single kettle + dry hopped beers were prepared. The overall sensory impression of the Saaz Special beers was comparable to Saaz hops. The profile of essential oils and hop aromas/flavours in the beer was partially different, but the hop aroma did not receive a worse rating than Saaz. The Saaz Special dry hopped beers were clearly distinguished from Saaz in triangle tests, but no preference was given to either variety. Based on the achieved results, the Saaz Special variety was listed among varieties recommended for the production of the beer with the Protected Geographical Indication of Czech Beer thanks to the achieved results.
\end{abstract}

Keywords: Czech beer, hop varieties, Saaz Special, sensory profile of beer, hop essential oils

\section{Introduction}

The breeding of a new hop variety takes from 10 to 20 years. Newly bred varieties are targeted for various uses, whether it is their high alpha acid content useful for basic hopping and beer bitterness, or the typical hop aroma profile and recently also new unusual aromas, i.e. 'flavour hop' varieties. Traditional aromatic hop varieties retain their place on the market. However, consumer preferences are changing and the need for innovation and development of new beer brands are the reason for breeding and use of new varieties with interesting aromas and bitterness profiles. In addition, a certain proportion of recommended hop varieties, whose chemical composition of resins and essential oils is defined (Commission, 2008), is prescribed for the production of beer with the Protected Geographical Indication of Czech Beer.

The brewing value of hops depends mainly on the content and composition of bitter acids and essential oils. Hop resins, i.e. bitter acids, give beer its bitterness, while hop derived volatile substances and essential oils provide aroma and flavour (Almaguer et al., 2014).

Most of the bitterness in beer is caused by $\alpha$-acids and their isomerised products, iso- $\alpha$-acids (Jaskula et al., 2010; Oladokun et al., 2015). Also humulinones, oxidation products of $\alpha$-acids (Algazzali et al., 2016), and hulupones, oxidation products of $ß$-acids, are the reason for the bitter taste (Dušek et al., 2014; Algazzali et al., 2016; Krofta et al., 2019). These oxidation products contribute significantly to the bitterness of beer only during dry hopping (Algazzali et al., 2016). Some polyphenols have bitter or bitter modifying properties (Oladokun et al., 2015; McLaughlin et al., 2008).

Bitterness is one of the key attributes of the sensory quality of beer. The sensory bitterness of beer includes various aspects of the bitter sensation, i.e. the intensity, 
the quality (pleasantness), but the rate of bitterness declines after swallowing. The perception of organoleptic bitterness is very individual and depends on the beer matrix (He et al., 2014).

The specific aroma that hops impart to beer depends on the hopping technology used during the brewing process. The composition of hop essential oils is rather diverse - with over 450 identified volatile substances (Inui et al., 2013). Overall, the aroma associated with hops is caused more by the synergistic mixture of the individual components than the effect of a single compound.

The components of hop essential oils are generally divided into three chemical groups: hydrocarbons, oxygen compounds and sulphur compounds. These groups may represent $60-80 \%, 20-40 \%$ and less than $1 \%$ of the total essential oils in hops respectively. Hydrocarbon terpenes are the main constituents of essential oils, the most common of which are mono-terpene $ß$-myrcene and sesquiterpenes $ß$-caryophyllene, $\alpha$-humulene, $ß$-farnesene and selinenes. Oxidized compounds include alcohols, ketones and esters. The group of terpene alcohols, such as linalool, geraniol, terpineol and farnesol, is very important for the sensorial profile of beer.

Most of the components of hop essential oils undergo significant changes during wort boiling and thus there are large losses of these substances. Only a few polar terpenoid compounds, such as linalool, geraniol, and humulene epoxides, can survive this process to some extent. These are the compounds that impart the hop flavour to the final beer (Fritsch and Schieberle, 2003; Kaltner and Mitter, 2009; Praet et al., 2016). During wort boiling, thermal and oxidative transformation of essential oils takes place. Then, during the main fermentation, the components of essential oils are transformed by yeast (Praet et al., 2012; Takoi et al., 2017) and the sorption of some essential oils, especially ß-myrcene to yeast cells takes place (Haslbeck et al., 2017). In dry hopping, the essential oil components are extracted into a mildly alcoholic solution of young beer. Following that they get partially sorbed or altered by the present yeast (Kaltner and Mitter, 2009; Forster and Gahr, 2013).

Sensory sensations of essential oils in beer are usually described as floral, citrusy, fruity, spicy or herbal aromas. Terpene alcohols, such as linalool and geraniol, are important components of the floral character of hop essential oils and beer. The contribution of hop essential oils is particularly pronounced in dry hops. The typical hop taste and aroma of kettle hopped beers are mainly formed by oxidized sesquiterpenes (Praet et al., 2016). It is known that the aroma of raw hops is often not comparable to the hop aroma in the final beer (Praet et al., 2012; Hanke et al., 2015). The impact on the sensory properties of beer can be predicted only from a detailed analysis of hops and just with some degree of probability. However, brewing tests are irreplaceable and they are gaining in importance especially when we wish to maintain the traditional sensory profile of beer.

The Saaz Special variety was obtained through selection from hybrid progeny of the Saaz semi early red bine variety and other breeding material. It is a medium to late variety of a fine aromatic type suitable for all hop growing areas; the variety was registered in 2012. The plant habitus is cylindrical to clublike with long side shoots and a high to very high number of cones in the upper third of the plant. The cones are narrowly ovate with slightly open bracts. Within the range of varieties of fine aromatic type, the yield of dry hops is high (Figure 1). It meets the requirements for processing in the form of pressed hop cones and pellets thanks to the medium content of alpha bitter acids in the range between $4.5-8.0 \% \mathrm{wt}$. and due to a very favourable ratio of $\alpha$ - and $\beta$ - bitter acids. The average content of cohumulone is $22.3 \%$ rel. and it is $40.6 \%$ rel. for colupulone. The total content of hop essential oils ranges between 0.8 and $1.9 \mathrm{ml} / 100 \mathrm{~g}$ with a high proportion of $ß$-farnesene, which is typical for the Saaz semi early red bine variety. The variety has been bred in order to preserve the typical chemotaxonomic characteristics of Saaz hops while achieving a higher hop yield and alpha bitter acid content.
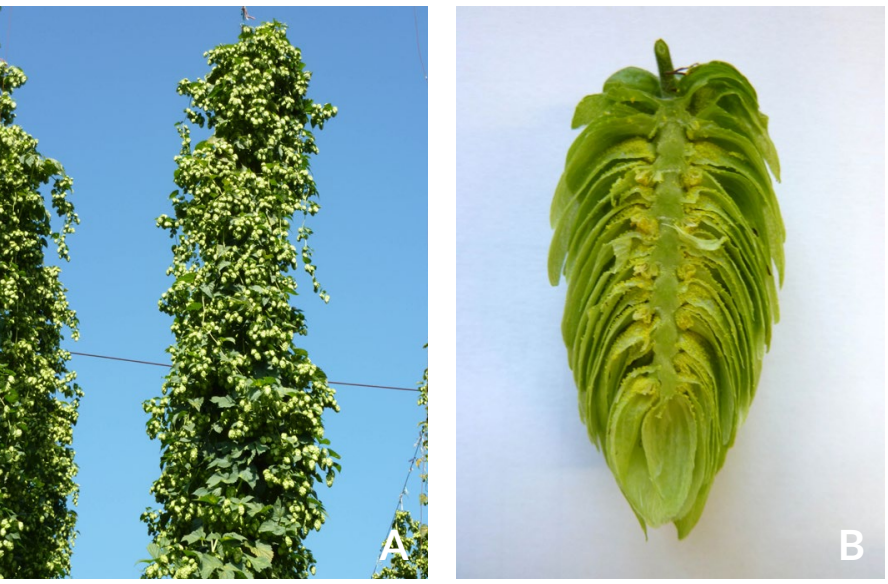

Figure 1 Saaz Special : A - hop plant; B - sectional view of hop cone

This article presents the results of three-year trials with the Saaz Special variety (bred by V. F. HUMULUS, Ltd.) in pilot brewing experiments. They were performed to describe the chemical and sensory profile of beers hopped with varieties potentially suitable for beer production with the PGI Czech Beer, both in kettle and dry hopped brews. 


\section{Material and methods}

\section{Brewing trials}

The brewing tests of the Saaz Special variety took place in a three-year cycle on a pilot scale $(2 \mathrm{hL})$ in the experimental brewery of the Research Institute of Brewing and Malting (RIBM). T90 pellets were used and dosed at conventional wort boiling, as well as dry hopping in lager tanks. The tested variety was compared with Saaz semi early red bine hops in single hopped brews.

Kettle hopped beers: The beer was produced in accordance with the rules of the PGI Czech Beer (Commission, 2008). The mashing of all malt brews of $12 \%$ pale lager was performed with a two-mash decoction procedure. Hop pellets T90 were added in three portions: $30 \%$ at the beginning, $50 \%$ after 30 minutes and $20 \%$ pellets 15 minutes before the end of the 90 minute atmospheric boil. The brews were hopped to the level of the planned bitterness of the beer of about 30 IBU. After removing the break in the whirlpool, cooling to a fermentation temperature of $10{ }^{\circ} \mathrm{C}$ and aeration to a dissolved oxygen content of $8 \pm 0.5 \mathrm{mg} / \mathrm{L}$, the wort was fermented with the yeast strain No. RIBM-95. The main fermentation took place in cylindro-conical tanks (CKT) where the maximum temperature was $12 \pm 0.1^{\circ} \mathrm{C}$. The green beer was transferred to lager tanks and the maturation time was 21 days at the temperature of $1-2{ }^{\circ} \mathrm{C}$. The beers were filtered through a plate filter and bottled on a machine filler.

Dry hopped beers: Seven days before the end of the maturation, $50 \mathrm{l}$ of beer were removed from the brews described above. Dry hopping was carried out by a static procedure with a dose of $3 \mathrm{~g}$ of hop pellets per 1 litre and with the variety identical to the variety in the kettle hopping.

\section{Analyses}

Analyses of hop pellets and beers were performed according to the EBC Analytics (Analytica EBC, 2010). Anthocyanogens were determined according to the MEBAK Analytics (MEBAK, 2011). The essential oils in hops and beer were determined by the method developed at RIBM (Mikyška et al., 2018). The sensory analysis of beer, including a detailed evaluation of hop aromas, was performed by a descriptive method developed at RIBM and the triangle test of difference. Sensory assessments were conducted by a trained panel of RIBM evaluators.

\section{Results and discussion}

Hops: The $\alpha$-bitter acid content in the hop samples selected for brewing tests was on average twice as high for Saaz Special than for Saaz. The proportion of cohumulone in $\alpha$-acids (22.3\% rel.) and the proportion of colupulone in $ß$-acids ( $40.6 \%$ rel.) is typical for fine aromatic varieties. The $\alpha$-/ß-acid ratio lower than 1 is the hallmark of the Saaz variety. The value in the Saaz Special tested samples was equal to 1 , but this ratio fluctuates considerably for all varieties both from year to year and also within one harvest. The profile of essential oils in Saaz Special shows certain differences compared to traditional Saaz. The content of linalool, $\beta$-caryophyllene, $\beta$-caryophyllene epoxide, $\alpha$-humulene, methylgeranate and cis-geraniol was higher in Saaz Special. On the contrary, the content of $\beta$-myrcene was lower in the tested hops belonging to this variety. However, the tested variety had a significant content of $\beta$-farnesene which is a specific marker of Saaz. The content of total polyphenols in Saaz Special was approximately 20\% lower compared to Saaz (Table 1). The concentration of total polyphenols in Czech beer is given by the PGI (130-230 mg/L), therefore their content in hops is also monitored.

Table 1 Content of bitter substances, polyphenols and essential oils in the tested hops

\begin{tabular}{|c|c|c|c|}
\hline Component & Unit & Saaz & Saaz Special \\
\hline a-acids & $\% w$ & 2.8 & 5.6 \\
\hline$\beta$-acids & $\% w$ & 3.5 & 5.6 \\
\hline alpha/beta ratio & & 0.80 & 1.03 \\
\hline total polyphenols & $\% \mathrm{w}$ & 4.7 & 3.8 \\
\hline TP/alpha ratio & & 1.71 & 0.67 \\
\hline xanthohumol & $\% w$ & 0.37 & 0.50 \\
\hline hop oils & $\mathrm{mg} / \mathrm{kg}$ & & \\
\hline$\alpha$ - and $\beta$-pinene & & 12 & 12 \\
\hline myrcene & $\mathrm{mg} / \mathrm{kg}$ & 973 & 249 \\
\hline limonene & $\mathrm{mg} / \mathrm{kg}$ & 6 & 10 \\
\hline linalool & $\mathrm{mg} / \mathrm{kg}$ & 16 & 37 \\
\hline$\beta$-caryophyllene & $\mathrm{mg} / \mathrm{kg}$ & 137 & 247 \\
\hline 4-terpineol & $\mathrm{mg} / \mathrm{kg}$ & 3 & 5 \\
\hline$\beta$-farnesene & $\mathrm{mg} / \mathrm{kg}$ & 323 & 466 \\
\hline a-humulene & $\mathrm{mg} / \mathrm{kg}$ & 652 & 1069 \\
\hline methylgeranate & $\mathrm{mg} / \mathrm{kg}$ & 9 & 21 \\
\hline a-terpineol & $\mathrm{mg} / \mathrm{kg}$ & 20 & 51 \\
\hline cis-geraniol & $\mathrm{mg} / \mathrm{kg}$ & 12 & 22 \\
\hline$\beta$-caryophyllene epoxide & $\mathrm{mg} / \mathrm{kg}$ & 41 & 102 \\
\hline farnesol & $\mathrm{mg} / \mathrm{kg}$ & 24 & 38 \\
\hline
\end{tabular}


Kettle hopped beers: The values of the basic chemical analysis of beers document the equilibrium of brews (Table 2). The influence of the tested variety on foaming, colour and other basic parameters of beers was not found. The analytical bitterness of beers was in the range of 34-37 IBU. The concentration of total polyphenols in Saaz Special was $25 \%$ lower compared to Saaz.

The spectrum of the evaluated essential oils in the beer represented 34 chemical individuals and included monoterpene hydrocarbons ( $\alpha$-pinene, $\beta$-pinene, myrcene, limonene), sesquiterpene hydrocarbons ( $ß$-caryophyllene, $ß$-farnesene, $\alpha$-humulene), monoterpene alcohols (linalool, 4-terpineol, $\alpha$-terpineol, cis-geraniol), oxidized sesquiterpenes ( $ß$-caryophyllene epoxide, farnesol), other hydrocarbons and esters. Essential oils in hops represent a wide range of substances where terpene hydrocarbons and alcohols dominate. A large part of these essential oils leaks or is chemically altered in the wort boiling process (Praet et al, 2016). Transformations and changes in concentration continue during fermentation by the biochemical action of the yeast and/or by the sorption
Table 2 Results of chemical analysis of kettle and kettle + dry hopped beers

\begin{tabular}{|l|c|c|c|c|c|}
\hline \multirow{2}{*}{ Parameter } & & \multicolumn{2}{c|}{ Kettle } & \multicolumn{2}{c|}{ Kettle+Dry } \\
\hline original extract & Unit & Saaz & $\begin{array}{c}\text { Saaz } \\
\text { Special }\end{array}$ & Saaz & $\begin{array}{c}\text { Saaz } \\
\text { Special }\end{array}$ \\
\hline attenuation apparent & $\% \mathrm{w}$ & 11.8 & 12.0 & 11.9 & 12.0 \\
\hline $\mathrm{pH}$ & $\%$ & 76.7 & 76.7 & 75.1 & 75.2 \\
\hline colour & & 4.44 & 4.50 & 4.52 & 4.48 \\
\hline bitterness & $\mathrm{EBC}$ & 13.3 & 12.5 & 12.7 & 12.7 \\
\hline iso-a-acids & $\mathrm{IBU}$ & 34 & 37 & 36 & 36 \\
\hline a-acids & $\mathrm{mg} / \mathrm{L}$ & 36.0 & 36.2 & 34.3 & 30.1 \\
\hline total polyphenols & $\mathrm{mg} / \mathrm{L}$ & 1.2 & 1.5 & 1.7 & 1.9 \\
\hline anthocyanogens & $\mathrm{mg} / \mathrm{L}$ & 239 & 176 & 258 & 198 \\
\hline
\end{tabular}

Kettle - Single kettle hopped beer; Kettle+Dry - Single kettle and dry hopped beer

on the surface of the yeast cells - typically $\beta$-myrcene (Takoi et al., 2017).

The profile of essential oils in kettle hopped beers was very similar in both varieties; slightly higher concentrations of $\beta$-myrcene, linalool, $\beta$-caryophyllene, $\alpha$-terpineol, cis-geraniol and farnesol were measured in the beers hopped with the Saaz variety (Figure 2).

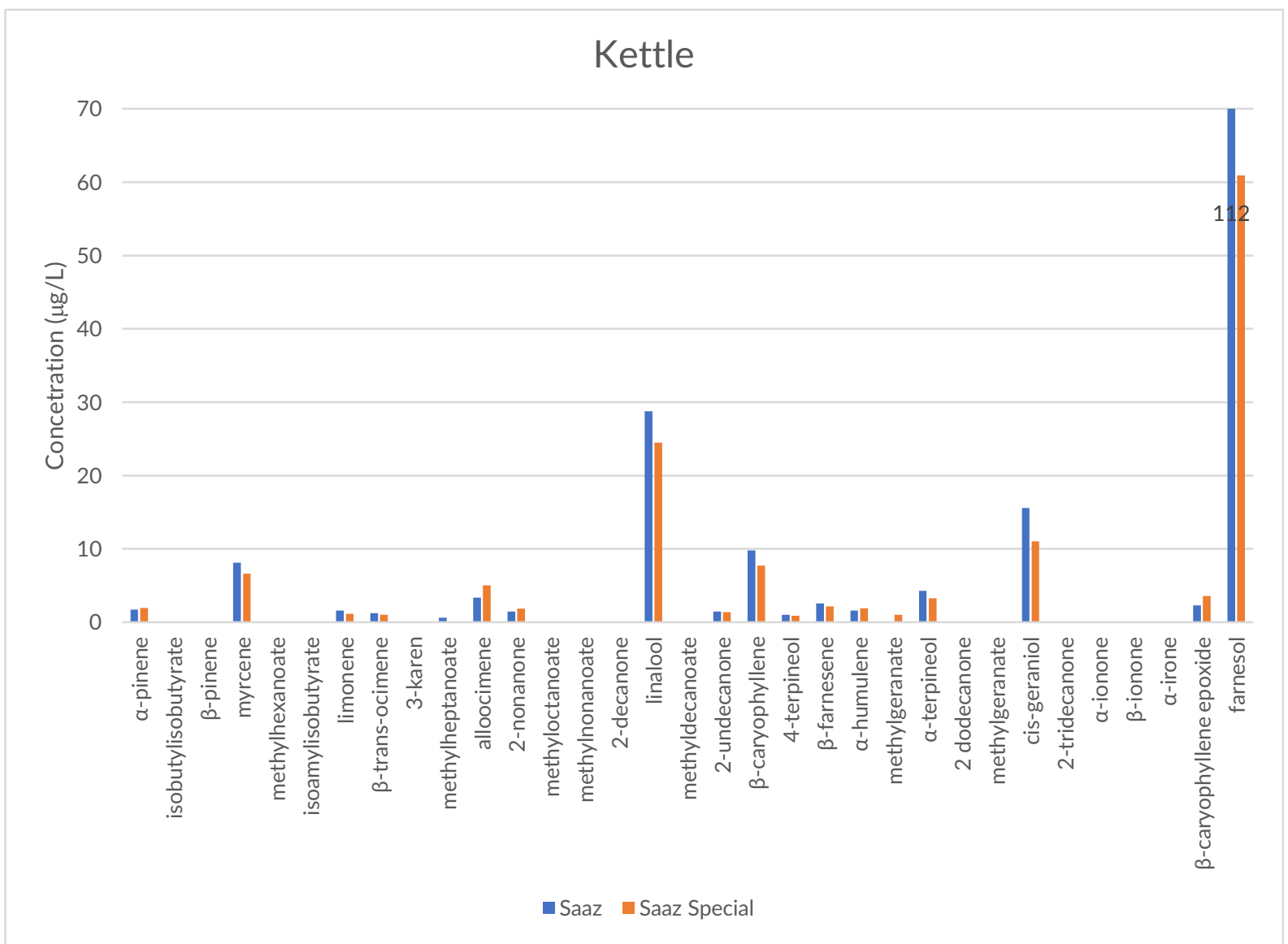

Figure 2 Concentration of essential oils in kettle hopped beer ( $\mu \mathrm{g} / \mathrm{L})$ 
The bitterness of beers was evaluated comprehensively (Mikyška and Čejka, 2010) The levels of evaluated descriptors such as the bitter perception after drinking, culmination of bitterness, lingering and character of bitterness of Saaz Special and Saaz hops were very balanced and differences between them were not significant. The same applies to the evaluation of the pleasantness of the hoppy aroma and hoppy flavour (Table 3). The 'balance', by which we mean the agreement between fullness, bitterness, sweetness, astringency and sourness, was equal for all the beers. The average overall sensory impression of the beers from both varieties was evaluated as equal.

The similarity of both varieties is evident in the profile of aroma intensity. This profile is associated with hops in beer generally (Figure 3). There were slightly higher values of hoppy, citrusy and herbal aromas in the beers hopped with Saaz, which corresponds to a higher concentrations of some essential oils in these beers (Figure 2). The triangle tests distinguished the beers hopped with Saaz Special from the beers hopped with Saaz in two out of three batches but without a clear preference of either variety (Table 4).
Dry hopped beers: The values of the basic chemical analysis of the beers document the equilibrium of the brews (Table 2). The dry hopped beers of both varieties had the total level of polyphenols and $\alpha$-acids approximately $10 \%$ higher than the kettle hopped beers. This is related to the cold extraction of these substances from hops (Forster and Gahr, 2013; Mikyška et al., 2018). Compared to the kettle hopped beers, a marked increase in the main components of terpenic essential

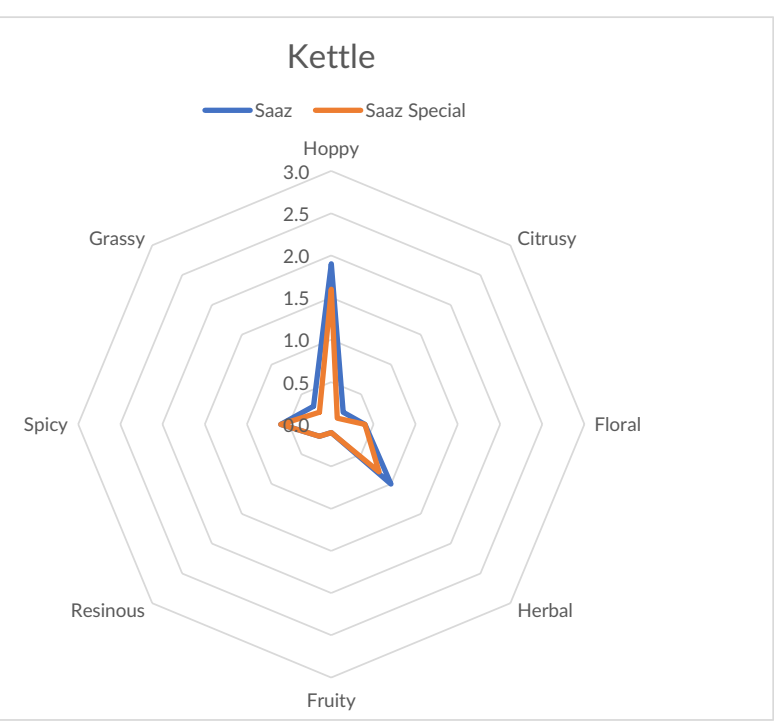

Figure 3 Hop aromas profile in kettle hopped beer Descriptors on the scale of $0-5$

Table 3 Results of descriptive sensorial analysis of kettle and kettle + dry hopped beers

\begin{tabular}{|c|c|c|c|c|c|c|c|c|}
\hline & \multicolumn{4}{|c|}{ Kettle } & \multicolumn{4}{|c|}{ Kettle+Dry } \\
\hline & \multicolumn{2}{|c|}{ Saaz } & \multicolumn{2}{|c|}{ Saaz Special } & \multicolumn{2}{|c|}{ Saaz } & \multicolumn{2}{|c|}{ Saaz Special } \\
\hline & $\mathbf{R}$ & SD & $\mathbf{R}$ & SD & $\mathbf{R}$ & SD & $\mathbf{R}$ & SD \\
\hline Carbonation & 2.7 & 0.2 & 2.4 & 0.1 & 2.5 & 0.4 & 2.5 & 0.4 \\
\hline Palate - fullness & 2.8 & 0.3 & 2.9 & 0.1 & 2.8 & 0.1 & 2.9 & 0.1 \\
\hline Bitterness & 2.1 & 0.0 & 2.1 & 0.3 & 2.3 & 0.1 & 2.3 & 0.2 \\
\hline Bitterness-culmination & 3.6 & 0.4 & 3.4 & 0.0 & 3.4 & 0.1 & 3.5 & 0.1 \\
\hline Bitterness-lingering & 2.4 & 0.2 & 2.3 & 0.1 & 2.2 & 0.1 & 2.4 & 0.1 \\
\hline Bitterness-character & 3.0 & 0.4 & 2.5 & 0.1 & 2.7 & 0.1 & 2.6 & 0.2 \\
\hline Astringency & 1.4 & 0.3 & 1.4 & 0.0 & 1.4 & 0.0 & 1.2 & 0.2 \\
\hline Sweet & 1.5 & 0.1 & 1.5 & 0.1 & 1.4 & 0.1 & 1.5 & 0.1 \\
\hline Sour & 1.6 & 0.0 & 1.5 & 0.1 & 1.4 & 0.0 & 1.6 & 0.2 \\
\hline Fruity/estery & 1.4 & 0.0 & 1.2 & 0.2 & 1.4 & 0.1 & 1.5 & 0.0 \\
\hline Hoppy & 1.8 & 0.1 & 1.7 & 0.1 & 2.2 & 0.0 & 2.7 & 0.2 \\
\hline Hop aroma - pleasantness & 4.1 & 0.5 & 3.9 & 0.5 & 3.4 & 0.6 & 3.0 & 0.5 \\
\hline Hop flavour - pleasantness & 3.8 & 0.4 & 3.6 & 0.5 & 3.1 & 0.3 & 3.1 & 0.7 \\
\hline Balance & 2.1 & 0.0 & 2.1 & 0.2 & 2.2 & 0.1 & 2.1 & 0.3 \\
\hline Overall impression & 3.8 & 0.2 & 3.7 & 0.3 & 3.8 & 0.4 & 3.4 & 0.5 \\
\hline
\end{tabular}

Kettle - Single kettle hopped beer; Kettle+Dry - Single kettle and dry hopped beer Descriptors on the scale 0-5; Overall impression 1-9 (descending scale) 
oils ( $\beta$-myrcene, limonene, linalool, $\alpha$-terpineol, 4-terpineol, cis-geraniol, $\beta$-caryophyllene epoxide) was observed. The profile of essential oils in the beer was very similar for both varieties (Figure 4).

Sensory bitterness, values of bitter perception after drinking, culmination of bitter perception, lingering and character of bitterness of the dry hopped beers from Saaz Special and the Saaz variety were rather similar and the differences between them were not significant. The same applies to the evaluation of the pleasantness of the hop derived aroma and flavour where the intensity of the hop aroma was higher for the beers hopped with Saaz Special (Table 3). The dry hopped beers of both varieties had a better score of hop aromas compared to the kettle hopped beers. The balance, i.e. the agreement between the fullness, bitterness, sweetness, astringency and sourness, was equal in all the beers. The overall sensory impression score for Saaz Special was on average 0.4 points better than for those of Saaz; the difference was not statistically significant.
Some differences between varieties are evident in the intensity profile of hop derived aromas in the dry hopped beers (Figure 5). A higher intensity of hoppy, resin and

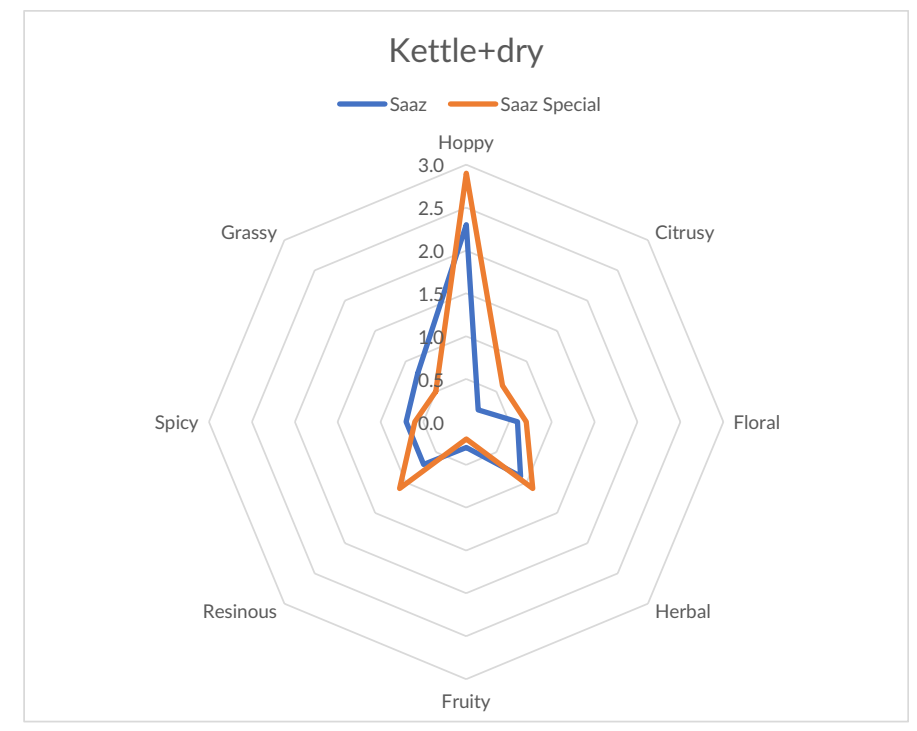

Figure 5 Hop aromas profile in kettle+dry hopped beer Descriptors on the scale of $0-5$

Figure 4 Concentration of essential oils in kettle+dry hopped beer ( $\mu \mathrm{g} / \mathrm{L})$

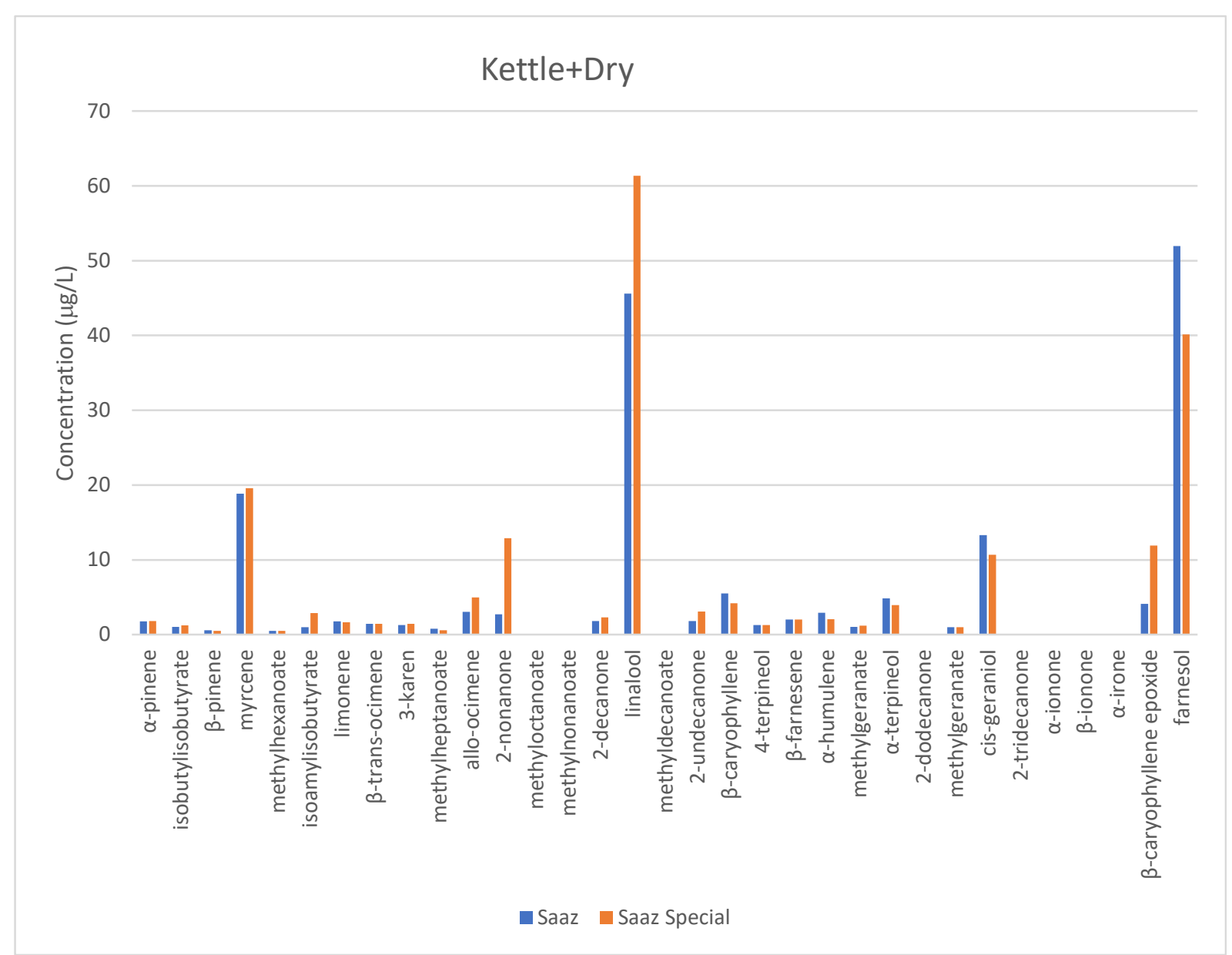


citrusy aromas was found in the beers hopped with Saaz Special. The individual perceived sensory aromas associated with hop essential oils are a complex perception in which several individuals from the spectrum of essential oils participate. The impact which the concentration together with the ratio of essential oils have on the sensory character of beer is a complex issue that is still subject of research (Kishimoto et al., 2006; Dresel et al., 2015; Mikyška et al. 2018). The triangle tests distinguished Saaz Special from the Saaz varieties in all the three pairs of brews. The results were similar for the kettle hopped beers where a preference of one variety was not clearly defined (Table 4).

\section{Conclusion}

Secondary metabolites of hops, bitter acids, essential oils and also hop polyphenols are transformed during brewing production and they contribute to the sensory properties of beer. Sensory properties of beer can be predicted from a detailed chemical and sensory analysis of hops only to a limited extent. Therefore it is necessary to evaluate the sensory potential of a certain variety in brewing tests.

The three-year pilot scale testing showed that the overall sensory impression of the beers kettle hopped with Saaz Special was comparable to the reference variety of traditional Saaz. Differences were found between the profiles of hop aroma in the beer from both varieties, but the aroma of Saaz Special was no less pleasant than the aroma of Saaz. Sensory triangles clearly distinguished Saaz Special from Saaz in two out of the three pairs of brews. The evaluators in the sensory panel did not distinctly prefer either of the varieties.

The potential of Saaz Special for dry hopping was also proven as the beers were rated slightly better compared to the Saaz dry hopped beers. The triangle tests clearly distinguished the two varieties, but neither variety was preferred by the evaluators.

From the chemotaxonomic point of view the fine aromatic variety of Saaz Special meets the requirements of the PGI Czech Beer for markers of bitter substances and essential oils. The sensory profile of the beers, which were kettle hopped with this hop, was not significantly different from the traditional Saaz. Therefore it was recommended by the Research Institute of Brewing and Malting for the production of Czech beer and included in the register of the recommended varieties maintained by the control body, i.e. the Czech Agriculture and Food Inspection Authority.

\section{Acknowledgement}

The study was supported by the Ministry of Agriculture of the Czech Republic within the institutional support MZE-R01918.

able 4 Results of triangle tests of kettle and kettle + dry hopped beers

\begin{tabular}{|c|c|c|c|c|}
\hline \multirow[b]{2}{*}{ Year } & \multirow{2}{*}{$\begin{array}{l}\text { Right re- } \\
\text { sponse }\end{array}$} & \multicolumn{2}{|c|}{ Saaz is } & \multirow{2}{*}{$\begin{array}{c}\text { Different } \\
\mathrm{P}=0.05\end{array}$} \\
\hline & & Better & Worse & \\
\hline \multicolumn{5}{|c|}{ Kettle hoped beer } \\
\hline 2019 & $7 / 9$ & 3 & 3 & YES \\
\hline 2018 & $4 / 9$ & 1 & 1 & NO \\
\hline 2017 & $8 / 12$ & 5 & 3 & YES \\
\hline \multicolumn{5}{|c|}{ Ketle+dry hoped beer } \\
\hline 2019 & $7 / 9$ & 3 & 3 & YES \\
\hline 2018 & $6 / 9$ & 4 & 2 & YES \\
\hline 2017 & $8 / 12$ & 3 & 4 & YES \\
\hline
\end{tabular}

\section{References}

Algazzali, V., Shellhammer, T. (2016). Bitterness Intensity of Oxidized Hop Acids: Humuli-nones and Hulupones. Journal of the American Society of Brewing Chemists, 74(1), 36-43. https://doi.org/10.1094/ ASBCJ-2016-1130-01

Almaguer, C., Schönberger, C., Gastl, M., Arendt, E. K., Becker, T. (2014). Humulus lupulus: A story that begs to be told. A review. Journal of The Institute of Brewing, 120(4), 289-314. https://doi.org/10.1002/jib.160

Analytica EBC (2010). European Brewery Convention, Carl-Hans Verlag, Nürenberg.

Commission (2008). České pivo (PGI). Official Journal of the EU C016/05, 23/01/2008, 0014-0022. Available from: https://eur-lex.europa. eu/legal-content/EN/TXT/?uri=0J:C:2008:016:TOC

Dresel, M., Praet, T., Van Opstaele, F., Van Holle, A., Naudts, D., De Keukeleire, D., De Cooman, L., Aerts, G. (2015). Comparison of the analytical profiles of volatiles in single-hopped worts and beers as a function of the hop variety. BrewingScience, 68 (1/2), 8-28.

Dušek, M., Olšovská, J., Krofta, K., Jurková, M., Mikyška, A. (2014). Qualitative determina-tion of $\beta$ acids and their transformation products in beer and hop using HR/AM-LC-MS/MS. Journal of Agricultural and Food Chemistry, 62(31), 7690-7697. https://doi.org/10.1021/jf501852r

Forster, A., Gahr, A. (2013). On the Fate of Certain Hop Substances during Dry Hopping. BrewingScience, 66(7/8), 93-103.

Fritsch, H. T., Schieberle, P. (2003). Changes in key aroma compounds during boiling of un-hopped and hopped wort. Proceedings of the 29th EBC Congress, Ireland - Dublin; Fachverlag Hans Carl: Nürnberg, Germany, CD-ROM.

Hanke, S., Schüll, F., Seigner, E., Engelhard, B., Lutz, A. (2015). Systematic brewing trials for evaluation and selection of new German hop breeding lines and future hop varieties. Proceedings of the 35th EBC Congress 24-28 May 2015, Porto, Portugal. L49.

Haslbeck, K., Bub, S., Schönberger, C., Zarnkow, M., Jacob, F., Coelhan, M. (2017). On the Fate of $\beta$-Myrcene during Fermentation - The Role of Stripping and Uptake of Hop Oil Components by Brewer's Yeast in Dry-Hopped Wort and Beer. BrewingScience, 70(11/12), 159-169. https://doi.org/10.23763/BrSc17-16haslbeck 
He, Y., Dong, J., Yin, H., Zhao, Y., Chen, R., Wan, X., Chen, P., Hou, X., Liu, J., Chen, L. (2014). Wort composition and its impact on the flavour-active higher alcohol and ester formation of beer: A review. Journal of The Institute of Brewing, 120(3), 157-163. https://doi. org/10.1002/jib.145

Inui, T., Tsuchiya, F., Ishimaru, M., Oka, K., Komura, H. (2013). Different beers with different hops. Relevant compounds for their aroma characteristics. Jurnal of the Agricultural and Food Chemistry, 61(20), 4758-4764. https://doi.org/10.1021/jf3053737

Jaskula, B., Aerts, G., De Cooman, L. (2010). Hop $\alpha$-acids isomerization and utilization: An experimental review. Cerevisia 35(3), 57-70. https:// doi.org/10.1016/j.cervis.2010.09.004

Kaltner, D., Mitter, W. (2009). Changes in hop derived compounds during beer production and ageing, Hop Flavour and Aroma. Proceedings of the 1st International Brewers Symposium, Master Brewers Association of the Americas, St. Paul, Minnesota, 37-46.

Kishimoto, T., Wanikawa, A., Kono, K., Shibata, K. (2006). Comparison of the odoractive compounds in unhopped beer and beers hopped with different hop varieties. Journal of Agricultural Food Chemistry, 54(23), 8855-8861. https://doi.org/10.1021/jf061342c

Krofta, K., Hervert, J., Mikyška, A., Dušek, M. (2019). Hop beta acids - from cones to beer. Proceedings of IV International Humulus Symposium, Yakima, Washington (USA) 2015, International Society for Horticultural Science, Leuven, Belgie 2019. ISBN 9789462612341

McLaughlin, I. R., Lederer, C., Shellhammer, T. H. (2008). Bitternessmodifying properties of hop polyphenols extracted from spent hop material. Journal of the American Society of Brewing Chemists, 66(3), 174-183. https://doi.org/10.1094/ASBCJ-2008-0619-01

MEBAK (2011). Collection of Brewing Analysis Methods of the Mitteleuropäische Brautechnische Analysenkommission (MEBAK), Freising-Weihenstephan, Germany, pp. 341.
Mikyška, A, Jurková, M. (2019). Analysis and prognosis of bitter acids content in Czech hop varieties - year 2018 and longterm comparisons and trends. Kvasny prumysl, 65(2), 25-35. https://doi. org/10.18832/kp2019.65.65

Mikyška, A., Olšovská, J., Slabý, M., Štěrba, K., Čerenak, A., Košir, I. J., Pavlovič, M., Kolenc, Z., Krofta, K. (2018). Analytical and sensory profiles of Slovenian and Czech hop genotypes in single hopped beers. Journal of The Institute of Brewing, 124(3), 209-221. https://doi. org/10.1002/jib.494

Mikyška, A., Čejka, P. (2013). Determination of sensorial bitterness of beer. Certified methodology, RIBM Prague. ISBN 978-80-86576-59-6

Oladokun, O., Smart, K., Hort, J., Cook, D. (2015). Impact of hop bitter acids and polyphenolic profiles on the perceived bitterness of beer. Proceedings of the 35th EBC Congress 24-28 May 2015, Porto, Portugal. L65.

Praet, T., Van Opstaele, F., De Causmaecker, B., Aerts, G., De Cooman, L. (2016). Heatinduced changes in the composition of varietal hop essential oils via wort boiling on a laboratory scale. Journal of the American Society of Brewing Chemists, 74(3), 212-223. https://doi. org/10.1094/ASBCJ-2016-3257-01

Praet, T., Van Opstaele, F., Jaskula-Goiris, B., Aerts, G., De Cooman, L. (2012). Biotransformations of hop-derived aroma compounds by Saccharomyces cerevisiae upon fermentation. Cerevisia, 36(4), 125132. https://doi.org/10.1016/j.cervis.2011.12.005

Takoi, K., Itoga, Y., Koie, K., Takayanagi, J., Kaneko, T., Watanabe, T., Matsumoto, I., Nomura, M. (2017). Systematic Analysis of Behaviour of Hop-Derived Monoterpene Alcohols During Fermentation and New Classification of Geraniol-Rich Flavour Hops. BrewingScience, 70(11/12), 177-186. https://doi.org/ 10.23763/BrSc17-17takoi 